PostScript

\section{Relationship between asthma severity and progression of Alzheimer's disease}

Severity of asthma is occasionally modulated by neuropsychiatric conditions. ${ }^{1}$ However little is known about the impact of cognitive decline on asthma severity. Cognitive decline is a core symptom in patients with Alzheimer's disease $(\mathrm{AD}) .^{2} \mathrm{AD}$ is a disease characterised by progressive cholinergic failure ${ }^{3}$ that could possibly reduce airway hyperresponsiveness to cholinergic stimulation and thus symptoms of asthma. Furthermore, the functions of $T$ lymphocytes - which play a crucial role in the development of chronic asthma-are partially impaired in patients with $\mathrm{AD}$ related diseases. ${ }^{4}$ We hypothesised that declining cognitive function might result in an improvement in asthma, and prospectively studied the contribution of the progression of $\mathrm{AD}$ to the clinical course of asthma.

Eight patients with asthma of mean (SE) duration 15.3 (0.9) years with concomitant AD were identified and prospectively followed for 5 years from 1995 to 2000. All subjects were treated with oral theophylline $(200 \mathrm{mg}$ twice daily) and a $200 \mu \mathrm{g}$ dose of fenoterol given by a flow driven inhaler as needed. Family members of the patients completed a diary card that recorded asthma symptoms, ${ }^{5}$ use of daily medication, and the number of hospital admis sions for asthma during the 5 years prior to study entry and the 5 year observation period. Cognitive function was assessed by MiniMental State Examination (MMSE) ${ }^{6}$ and sputum eosinophil counts ${ }^{7}$ and methacholine challenge tests ${ }^{8}$ were performed both at enrolment in the study and at the end. Informed consent was obtained from each patient, his or her family, and an attending physician.

MMSE scores were significantly decreased during the 5 year observation period in all subjects (table 1). Overall attack frequency and severity of asthma symptoms significantly decreased during the progression of cognitive impairment in all but one asthmatic subject with $\mathrm{AD}$ (table 1). Induced sputum obtained at the end of the study from seven subjects with improved asthma had a significantly lower percentage of eosinophils than at the start of the study $(2.2(0.4) \%$ at end point $v 10.7(2.8) \%$ at baseline, $\mathrm{n}=7, \mathrm{p}=0.008)$, but there were no significant differences in the mean percentages of macrophages, neutrophils, or lymphocytes. By contrast, in all subjects the minimum cumulative dose of methacholine that induced an increase in respiratory resistance at the end of the study was not significantly different from that obtained at study enrolment $(0.426(0.252) \mathrm{U}$ at end point $v 0.368(0.144) \mathrm{U}$ at enrolment in the study, $\mathrm{n}=8, \mathrm{p}=0.26)$. No other precipitating factors for asthma were identified during the study period in any subject.

Both overall attack frequency and severity of asthma symptoms decreased significantly during the progression of cognitive impairment in asthma patients with AD. However, peripheral cholinergic function might not be impaired in the airway in patients with $\mathrm{AD}$ despite an extensive loss of central cholinergic neurons. ${ }^{3}$ It has been reported that the nervous system may modulate immunological and inflammatory responses. ${ }^{9}$ Our results suggest that progression of $\mathrm{AD}$ might provide an ameliorating effect on the clinical course of asthma, probably due to alterations in the immunological responses including eosinophilic inflammation in the airway.

T Ohrui, H Arai, M Ichinose, T Matsui, M Yamaya, H Sasaki Department of Geriatric and Respiratory Medicine, Tohoku University School of Medicine, Senda 980-8574, Japan

Correspondence to: Dr H Sasaki, Department of Geriatric and Respiratory Medicine, Tohoku University School of Medicine, 1-1 Seiryo-machi, Aoba-ku, Sendai 980-8574, Japan dept@geriat.med.tohoku.ac.jp

\section{References}

1 Campbell DA, Yellowlees PM, McLennan G, et al. Psychiatric and medical features of near fatal asthma. Thorax 1995:50:254-9.

2 McKhaan G, Drachman D, Folstein $M$, et al. Clinical diagnosis of Alzheimer's disease: Report of the NINCDS-ADRDA work group under auspices of the Department of Health and Human Services Task Force on Alzheimer's disease. Neurology 1984.34:939-44.

3 Davis KL, Mohs RC, Martin D, et al. Cholinergic markers in elderly patients with early signs of Alzheimer's disease. JAMA 1999;281:1401-6.
If you have a burning desire to respond to a paper published in Thorax, why not make use of our "rapid response" option?

Log on to our website (www.thoraxjinl.com), find the paper that interests you, and send your response via email by clicking on the "eletters" option in the box at the top right hand corner.

Providing it isn't libellous or obscene, it will be posted within seven days. You can retrieve it by clicking on "read eletters" on our homepage.

The editors will decide as before whether to also publish it in a future paper issue.

4 Park E, Alberti J, Mehta P, et al. Partial impairment of immune functions in periphera blood leukocytes from aged men with Down's syndrome. Clin Immunol 2000;95:62-9.

5 Nakasato H, Ohrui T, Sekizawa K, et al. Prevention of severe premenstrual asthma attacks by leukotriene receptor antagonist. $J$ Allergy Clin Immunol 1999;104:585-8.

6 Folstein MF, Folstein SE, McHugh PR. "Mini-Mental State": a practical method for grading the cognitive state of patients for clinicians. J Psychiatr Res 1975;12:189-98.

7 Fahy JV, Liu J, Wong H, et al. Cellular and biochemical analysis of induced sputum from asthmatic and from healthy subjects. Am Rev Respir Dis 1993;147:1126-31.

8 Takishima T, Hida W, Sasaki H, et al. Direct-writing recorder of the dose-response curves of the airway to methacholine. Chest 1981;80:600-6.

9 Shalit F Sredni B, Brodie C, et al. T lymphocyte subpopulations and activation markers correlate with severity of Alzheimer's disease. Clin Immunol Immunopathol $1995 \cdot 75 \cdot 246-50$

\section{IL-1 haplotypes and lung function decline}

We read with interest the paper by Joos et al ${ }^{1}$ on the association of IL-1 gene haplotypes with decline in lung function in smokers and share their view on a possible role of IL-1 genetics in inflammatory respiratory diseases. We have analysed the same polymorphism by

Table 1 Assessment of asthma severity and change in cognitive function at study entry (baseline) and 5 year follow up (end point) in asthma patients with Alzheimer's disease

\begin{tabular}{|c|c|c|c|c|c|c|c|c|c|c|}
\hline \multirow[b]{2}{*}{ Case } & \multirow[b]{2}{*}{ Age $(y)$} & \multirow[b]{2}{*}{ Sex } & \multicolumn{2}{|c|}{ MMSE score } & \multicolumn{2}{|c|}{ Asthma symptom score } & \multicolumn{2}{|c|}{ Daily inhaler puffs } & \multicolumn{2}{|c|}{$\begin{array}{l}\text { Number of hospital } \\
\text { admissions for asthma }\end{array}$} \\
\hline & & & Baseline & End point & Baseline & End point & Baseline & End point & Baseline & End point \\
\hline 1 & 67 & $M$ & 23 & 18 & 6.4 & 1.2 & 1.3 & 0 & 2 & 0 \\
\hline 2 & 66 & $M$ & 21 & 16 & 8.6 & 2.2 & 1.4 & 0 & 2 & 0 \\
\hline 3 & 70 & $\mathrm{~F}$ & 23 & 17 & 10.2 & 1.6 & 2.4 & 0 & 3 & 1 \\
\hline 4 & 65 & $M$ & 22 & 15 & 7.8 & 1.2 & 2.6 & 1.4 & 3 & 0 \\
\hline 5 & 65 & $\mathrm{~F}$ & 21 & 16 & 7.5 & 0.4 & 3.3 & 1 & 2 & 0 \\
\hline 6 & 69 & $\mathrm{~F}$ & 23 & 17 & 9.4 & 3.6 & 1.9 & 0.4 & 3 & 0 \\
\hline 7 & 66 & $F$ & 22 & 16 & 9.2 & 2.4 & 2.2 & 0 & 2 & 0 \\
\hline 8 & 68 & $M$ & 23 & 21 & 7.6 & 7.4 & 2.8 & 2.6 & 3 & 2 \\
\hline Mean (SE) & $67.0(0.7)$ & & $22.3(0.3)$ & $17.0(0.7)$ * & $8.4(0.5)$ & $1.8(0.4) \dagger$ & $2.2(0.3)$ & $0.4(0.2) \ddagger$ & $2.4(0.2)$ & $0.1(0.1) \S$ \\
\hline
\end{tabular}

MMSE=Mini-Mental State Examination; SE=standard error

${ }^{*} p<0.0001$ (Wilcoxon rank test) compared with baseline data in all asthma patients with Alzheimer's disease; $† p<0.0001 ; \ddagger p=0.0001 ; \S p<0.0001$

compared with baseline data in seven asthma patients with Alzheimer's disease (cases 1-7). 
Table 1 Decline in $\mathrm{FEV}_{1}$ ( $\mathrm{ml} /$ year) in non-smoking asthmatics and controls in different putative IL- 1 haplotypes

\begin{tabular}{|c|c|c|c|c|c|c|}
\hline IL-1 haplotype & $\begin{array}{l}\text { (1) ILIRNA2/ } \\
\text { ILIB-511T }\end{array}$ & $\begin{array}{l}\text { (2) ILIRN A2/ } \\
\text { ILIB -511C }\end{array}$ & $\begin{array}{l}\text { (3) ILIRNAI/ } \\
\text { ILIB-511T }\end{array}$ & $\begin{array}{l}\text { (4) ILIRN AI/ } \\
\text { ILIB -511C }\end{array}$ & p value* & $\begin{array}{l}\text { Post hoc tests between } \\
\text { allele groups } \dagger\end{array}$ \\
\hline $\begin{array}{l}\text { Non-smoking controls } \\
(\mathrm{n}=124)\end{array}$ & $\begin{array}{l}41.8(13.8) \\
(n=54)\end{array}$ & $\begin{array}{l}44.8(12.3) \\
(n=32)\end{array}$ & $\begin{array}{l}50.7(111.2) \\
(n=7)\end{array}$ & $\begin{array}{l}45.5(19.4) \\
(n=31)\end{array}$ & 0.27 & Not tested \\
\hline $\begin{array}{l}\text { Non-smoking new asthma } \\
\text { cases }(n=40)\end{array}$ & $\begin{array}{l}63.2(24.6) \\
(n=18)\end{array}$ & $\begin{array}{l}37.7(20.7) \\
(n=4)\end{array}$ & $\begin{array}{l}30.9(16.9) \\
(n=4)\end{array}$ & $\begin{array}{l}51.0(24.8) \\
(n=14)\end{array}$ & 0.0443 & $\begin{array}{l}3<1, p=0.02 \\
2<1, p=0.06\end{array}$ \\
\hline
\end{tabular}

*Two way analysis of variance; $\mathrm{TLSD}$ test of means.

the same methods in adult incident non-smoking asthmatic patients and nonsmoking controls. Our results indicate that the association of IL-1 genetics with rate of decline in lung function is not limited to smokers.

New adult asthma cases and controls were selected from a cohort of the Mini-Finland Health Survey (MFHS) and later reevaluated. A more detailed description of the methods used in MFHS has been published elsewhere. ${ }^{2}$ The accuracy of the method of asthma case ascertainment has also recently been described. ${ }^{3}$ IL-1 haplotypes were found to be significantly associated with the rate of decline of lung function in non-smoking incident cases of asthma (new asthma during follow up) but not in controls (table 1). Of the individual haplotypes, Joos et al found that ILIRN AI/ILIB -5IIT was associated with a rapid decline of lung function in smokers and ILIRN A2/ILIB -51IT with a slow decline. In our control group the observed differences were not significant. Surprisingly, in the asthma group the haplotypes had the opposite effects from those in smokers: ILIRN AI/ILIB $-511 T$ was associated with a slower decline in lung function and ILIRN A2/ILIB -511T with a more rapid decline. ILIRN A2/ILIB $-511 T$ has previously been found to be associated with many inflammatory diseases. ${ }^{4}$ The function of these haplotypes would therefore appear to be disease specific.

J Karjalainen

Tampere University Hospital, Department of Respiratory Medicine and Medical School, FIN-33014 University of Tampere, Finland; jussi.karjalainen@uta.fi

J Hulkkonen, $M$ Hurme

Tampere University Hospital, Centre for Laboratory Medicine and Department of Microbiology and Immunology

\section{References}

1 Joos L, Mclntyre L, Ruan J, et al. Association of IL-1 beta and IL-1 receptor antagonist haplotypes with rate of decline in lung function in smokers. Thorax 2001;56:863-6.

2 Von Hertzen L, Reunanen A, Impivaara O, et al. Airway obstruction in relation to symptoms in chronic respiratory disease: a nationally representative population study. Respir Med 2000;94:356-63.

3 Karjalainen A, Kurppa K, Martikainen R, et al. Work is related to a substantial portion of adult-onset asthma incidence in the Finnish population. Am J Respir Crit Care Med 2001;164:565-8.

4 Hurme M, Lahdenpohia N, Santtila S. Gene polymorphisms of interleukins 1 and 10 in infectious and autoimmune diseases. Ann Med 1998;30:469-73.

\section{Authors' reply}

Karajalainen and colleagues present interesting data on the relationship of IL- $1 \beta$ and IL- 1 receptor antagonist haplotypes and the rate of decline of lung function in incident asthmatic subjects in a Finnish cohort. We reported that the ILIRN AI/ILIB -511T haplotype was associated with a more rapid decline in lung function in smokers in the Lung Health Study; in contrast, they found that this same haplotype was associated with a slower rate of decline in lung function in patients with asthma. The authors suggest that this apparent contradiction may be because the function of these haplotypes is disease specific. We agree that a different effect of the same haplotype could occur because of fundamental differences in the pathophysiological processes which cause airflow obstruction in asthma and chronic obstructive pulmonary disease (COPD). In asthma, CD4+ Th2 cells underlie persistent eosinophilic inflammation and remodelling in medium sized and larger airways. In COPD, neutrophils and CD8 + cells appear to play an important role in the airflow limitation by causing proteolytic destruction of peripheral lung parenchyma and fibrous scarring of the small membranous and respiratory bronchioles. Although inflammation appears to be central to both processes, the roles of IL- $1 \beta$ and of IL-1 receptor antagonist in these conditions is unknown and it is possible that the polymorphisms that are responsible for this haplotype could have opposite effects.

Alternatively, these apparently contradictory results could be due to different genetic histories of the two study groups. Our study group was taken from the white population in the United States whereas Karjalainen et al studied Finnish individuals. It may be that the polymorphisms which are typed to establish these haplotypes do not, by themselves, change the function or level of expression of the IL proteins but are in linkage disequilibrium with a causal polymorphism(s). In this case, the ILl allelic associations could be different in different populations. The bottleneck in the genetic history of the Finnish people could have established a founder effect and resulted in the function altering allele being found on a different genetic background from that in the white population of the United States.

Whatever the correct explanation, these results support the growing evidence that

Table 1 Demographic data, site, phenotypic and genotypic resistance of the seven resistant study isolates

\begin{tabular}{|c|c|c|c|c|c|c|}
\hline \multirow[b]{2}{*}{ Isolate } & \multirow[b]{2}{*}{ Age } & \multirow{2}{*}{$\begin{array}{l}\text { Country of } \\
\text { birth }\end{array}$} & \multirow[b]{2}{*}{ Site of TB } & \multirow{2}{*}{$\begin{array}{l}\text { Drug } \\
\text { resistance }\end{array}$} & \multicolumn{2}{|c|}{ Resistance genotype } \\
\hline & & & & & Isoniazid & Rifampicin \\
\hline 1 & 24 & Nigeria & Pulmonary & INH/RIF & Wild type & rpoB mutation \\
\hline 2 & 21 & Somalia & Pulmonary & INH & katG mutation & Wild type \\
\hline 3 & 40 & Zaire & Pulmonary & INH & inhA mutation & Wild type \\
\hline 4 & 17 & Zaire & Pulmonary & INH & inhA mutation & Wild type \\
\hline 5 & 20 & Zaire & Pulmonary & INH & inhA mutation & Wild type \\
\hline 6 & 42 & UK & Pulmonary & INH & inhA mutation & Wild type \\
\hline 7 & 44 & Somalia & Sternum & $\mathrm{PZ}$ & Wild type & Wild type \\
\hline
\end{tabular}

INH=isoniazid; RIF=rifampicin; PZ=pyrazinamide. Isolates 3 and 5 had indistinguishable IS6 110 types. Isolates 1 and 4 were not typable due to insufficient culture and the banding pattern of isolate 6 was uninterpretable. genetic variation at the IL- 1 locus is important in modulating the severity and/or functional consequences of a number of inflammatory conditions.

L Joos, P D Paré, A Sandford UBC McDonald Research Laboratories and CAPTURE Center, St Paul's Hospital, University of British Columbia, Vancouver, BC V6Z 1Y6, Canada; asandford@mrl.ubc.ca

\section{Molecular analysis of drug resistant TB}

Since the mid 1980s the number of notified cases of TB in the UK has continued to rise with the largest increases noted in London and inner city areas. ${ }^{1}$ King George Hospital in Goodmayes, Essex provides clinical services to a population of approximately $230000 ; 17 \%$ are non-white subjects including immigrants rom countries with high rates of $M$ tuberculosis infection and drug resistance. From September 1996 to July 199747 adult cases of culture proven TB were identified including seven with drug resistant isolates. None was identified by contact tracing. A previous TB audit of African born patients revealed a high rate of drug resistance $(6 / 24(25 \%))$ and delays in obtaining drug sensitivities which could have been detrimental to patient management.

Under these circumstances the rapid identification of drug resistance in $M$ tuberculosis isolates would have been helpful. The aim of this study was to determine retrospectively he usefulness of PCR-reverse hybridisation methods for screening for mutations within or adjacent to $M$ tuberculosis genes associated with rifampicin $(r p o B)$ and isoniazid (inhA, $k a t G$, and $a h p C)$ resistance. We also determined whether resistance genotyping combined with IS6110 typing could help to identify clusters of drug resistant cases not previously identified by contact tracing.

Seven consecutive drug resistant $M$ tuberculosis culture isolates were analysed for rifampicin and isoniazid resistance and the results were compared with conventional susceptibility testing. The commercially available 
assay INNO-LiPA Rif.TB ${ }^{3}$ was used to detect $r p o B$ mutations and an in-house PCR-reverse hybridisation line probe was used to detect mutations in or adjacent to the kat $G$, inhA, and ahpC genes. ${ }^{4}$ The isolates were also IS6110 typed. ${ }^{5}$

The single rifampicin and isoniazid resistant isolate had an $r p o B$ gene mutation associated with rifampicin resistance (table 1). Four of the five isoniazid resistant isolates had the same single point mutation upstream of the inhA gene and the other a single kat G point mutation. Isolates 3 and 5 had indistinguishable IS61 10 types that could represent isolates where recent transmission had occurred. No mutations were detected in the 40 fully susceptible isolates.

PCR-reverse hybridisation methods were highly sensitive and specific at detecting mutations that predict for isoniazid and rifampicin resistance. We also demonstrated that different point mutations can be used to discriminate between isoniazid resistant isolates. We believe that with automation and the addition of oligonucleotide probes designed to detect mutations associated with pyrazinamide $(p n c A)^{6}$ and ethambutol $(e m b B)^{7}$ resistance, a system capable of detecting resistance to four front line antituberculous drugs will soon be commercially available. Rapid resistance detection by PCR-reverse hybridisation is likely to have a major impact on patient management and our understanding of the epidemiology of drug resistant TB.

\section{Acknowledgements}

We would like to thank the Steering Group Members of the "Molecular Epidemiology of Tuberculosis in London" for allowing us access to their $M$ tuberculosis IS6110 type database and to the Mycobacterial Reference Laboratory (Dulwich) for conventional susceptibility testing.

M Melzer, T J Brown, G L French Department of Infection, St Thomas' Hospital, London SE 1 7EH, UK

A Dickens, T D McHugh

Department of Medical Microbiology, Royal Free and University College Medical School, London NW3 2PF, UK

L R Bagg, R A Storring, S Lacey King George Hospital, Goodmayes, Essex IG3 8YB, UK

Correspondence to: $\operatorname{Dr} M$ Melzer, Department of Infection, St Thomas' Hospital, London SE 1 7EH, UK; markmelzer@hotmail.com

\section{References}

1 Pearson AD, Hamilton GR, Healing TD, et al. Summary of a report of the working party on tuberculosis of the London group of Consultants in Communicable Disease Control. J Hosp Infect 1996;33: 165-79.

2 Melzer M, Storring RA, Lacey S, et al. Tuberculosis in African born adults: can we improve clinical practice? J R Coll Physicians 1998;32: 493-4.

3 Cooksey RC, Morlock GP, Glickman S, et al. Evaluation of a line probe assay kit for characterization of rpoB mutations in rifampicin-resistant Mycobacterium tuberculosis isolates from New York City. J Clin Microbiol 1997;35:1281-3.

4 Brown TJ, French GL. Genotypes associated with isoniazid resistance in Mycobacterium tuberculosis isolates seen at a London teaching hospital. J Microbiol Methods 1999; 38:226

5 van Embden JDA, Cave MD, Crawford JT, et al. Strain identification of Mycobacterium tuberculosis by DNA fingerprinting: recommendations for a standardised methodology. J Clin Microbiol 1993; 31:406-9.
6 Hirano K, Takahashi M, Kazumi Y, et al. Mutations in pncA is a major mechanism of pyrazinamide resistance in Mycobacterium

1998;78:117-22.

7 Sreevatson S, Stockbaver KE, Pan X, et al. Ethambutol resistance in Mycobacterium tuberculosis: critical role of embB mutations. Antimicrob Agents Chemother

1997;41:1677-81.

\section{Lung bullae and marijuana}

A previous paper from this hospital described apical lung bullae in four young male marijuana smokers, three West Indian and one Caucasian. ${ }^{1}$ Two further cases were recently reported, both in Caucasian men. ${ }^{2}$ We describe three further cases (one woman) with large upper lobe bullae. All are Caucasian and had a prolonged history of heavy marijuana smoking with an alpha ${ }_{1}$-antitrypsin level within the normal range (table). These further cases support the view that marijuana may have a causal role in the development of lung bullae. We suggest that a detailed marijuana smoking history is taken from patients of all ethnic origins with upper lobe bullae.

C S Thompson, R J White

Department of General Medicine, Frenchay Hospital, Bristol BS16 1LE, UK

Correspondence to: Dr C S Thompson, Department of General Medicine, Frenchay Hospital, Bristol BS16 1LE, UK.

\section{References}

1 Johnson MK, Smith RP, Morrison D, et al. Large lung bullae in marijuana smokers. Thorax 2000:55:340-2.

2 Rawlins R, Carr CS, Brown KM, et al. Minerva. BM 2001;323:1012.

\section{Pathophysiology of COPD}

The paper by Dentener et al is interesting and contributes to the understanding of the pathophysiology of chronic obstructive pulmonary disease (COPD). It is becoming clear that COPD is a systemic syndrome, and this paper suggests some potential mechanisms. However, a number of issues merit further comment.

It is noted that, in healthy controls, there is a wide range of $\mathrm{C}$ reactive protein (CRP) values extending well beyond what would be considered to be the normal range. The reason for this is unclear, but it does suggest that these individuals are not as healthy as tuberculosis. Tuberc Lung Dis

described. In addition, patients with stable COPD have a range of CRP values that also extend beyond this normal range. This is not consistent with previous studies, which suggests that, in patients with stable COPD, the range of CRP values falls within the normal range. ${ }^{2}$ Although patients with bronchiectasis were excluded, it is possible that undiagnosed bronchiectasis may have been present. Previous work has shown that $29 \%$ of patients presenting with what appeared to be stable COPD had CT evidence of at least mild bronchiectasis. ${ }^{3}$ This could conceivably explain a wider range of CRP levels. In addition, it is interesting that after just 5 days of treatment for an acute exacerbation of COPD the CRP had returned to a level below that of the stable cohort in the study. Since standard treatment for an exacerbation is able to achieve this in just a few days, it suggests that the stable group may have contained individuals that were in fact not so stable.

The authors allude to the potential confounding effect of systemic corticosteroids in the study. The changes in total leucocyte count during the exacerbation are likely to be due to the effect of prednisolone, making it difficult to interpret the changes in leucocyte count. In stable patients the action of corticosteroids may also confound the results. It is possible that, even in patients using inhaled corticosteroids, leucocyte numbers could be affected since there may be significant bioavailability at higher doses. Leucocyte count should therefore not be used as a marker for systemic inflammation in these patients.

Finally, it would appear that the exacerbations of COPD might have been mild, despite the presence of severe COPD on lung function criteria. Although $\mathrm{PaCO}_{2}$ was slightly higher and $\mathrm{PaO}_{2}$ slightly lower than in the stable group, these differences were small in magnitude. The $\mathrm{pH}$ was not significantly different and, in fact, the stable group contained individuals with a lower $\mathrm{pH}$ (range 7.30-7.50) than in the exacerbated group ( $\mathrm{pH} 7.34-7.49$ ). Although the mean CRP level appears higher than in stable patients, the range does not differ significantly. This may therefore have led to a less profound change in inflammatory markers than might have been expected, and a study looking at more severe exacerbations may be more revealing.

M Kelly

Department of Respiratory Medicine, Belfast City Hospital, Belfast BT9 7AB, UK; m.g.kelly@qub.ac.uk

Table Characteristics at presentation of three cases of apical lung bullae in marijuana smokers

\begin{tabular}{|c|c|c|c|}
\hline & Case 1 & Case 2 & Case 3 \\
\hline Age on presentation (years) & 33 & 45 & 38 \\
\hline Sex & Male & Female & Male \\
\hline Ethnic origin & Caucasian & Caucasian & Caucasian \\
\hline Tobacco smoking history & 9 pack years & 10 pack years & 20 pack years \\
\hline Marijuana smoking history & $\begin{array}{l}2-3 \text { joints/day, } \\
\text { "heavy" } 10 \text { years }\end{array}$ & $\begin{array}{l}\text { Weekends/evenings, } \\
\text { "moderate" } 10 \text { years }\end{array}$ & $\begin{array}{l}0.25 \text { oz } \\
\text { marijuana/week, } \\
\text { "heavy" } 24 \text { years }\end{array}$ \\
\hline $\begin{array}{l}\text { Alpha,-antitrypsin }(\mathrm{g} / \mathrm{l}) \\
\text { (normal range } 1.1-2.1 \text { ) }\end{array}$ & 1.4 & 2.3 & 1.6 \\
\hline FEV (I) (\% predicted) & $2.7(64)$ & $2.4(96)$ & $3.7(90)$ \\
\hline FVC (I) (\% predicted) & $4.3(85)$ & $3.3(112)$ & $4.7(94)$ \\
\hline $\mathrm{FEV}_{1} / \mathrm{FVC}(\%)$ & 63 & 73 & 79 \\
\hline TLCO (\% predicted) & $9.44(81)$ & $4.99(62)$ & - \\
\hline Kco (\% predicted) & $1.44(88)$ & $1.10(64)$ & - \\
\hline
\end{tabular}

$\mathrm{FEV}_{1}=$ forced expiratory volume in 1 second; $\mathrm{FVC}=$ forced vital capacity; $\mathrm{TLCO}=$ carbon monoxide transfer factor; $\mathrm{KCO}=$ carbon monoxide transfer coefficient. 


\section{References \\ 1 Dentener MA, Creutzberg EC, Schols AMWJ, et al. Systemic anti-inflammatory mediators in COPD: increase in soluble interleukin 1 receptor II during treatment of exacerbations. Thorax 2001;56:721-6. \\ 2 Gompertz S, Bayley DL, Hill SL, et al. \\ Relationship between airway inflammation and the frequency of exacerbations in patients with smoking related COPD. Thorax $2001 ; 56: 36-41$ \\ 3 O' Brien C, Guest PJ, Hill SL, et al. Physiological and radiological characterisation of patients diagnosed with chronic obstructive pulmonary disease in primary care. Thorax 2000;55:635-42.}

\section{Authors' reply}

Dr Kelly has some concerns about the levels of $\mathrm{C}$ reactive protein (CRP) in the healthy controls and patients with clinically stable COPD in our study. The control group used consisted of randomly selected subjects over 50 years of age and living in the same area as the patients. These subjects had no evidence of COPD based on questionnaires and lung function testing, did not exhibit any acute or chronic disease, and were not taking medication. Based on these selection criteria, this group was considered a healthy population control group. Although two of the 23 control subjects had enhanced CRP levels, the reason for which is unknown, they were not excluded in order to prevent bias. Non-parametric tests were used to compare the CRP levels between controls and COPD patients, and therefore the results are not affected by these two outliers.

Concerning the diagnosis of COPD, all patients in our study underwent high resolution computed tomographic scanning to exclude the presence of bronchiectasis.

There is increasing evidence that COPD is characterised by systemic effects which, among other factors, are reflected by enhanced circulating levels of inflammatory mediators in the circulation. ${ }^{1}$ In line with the observations of increased levels of the acute phase proteins CRP and lipopolysaccharide binding protein (LBP) in patients in a clinically stable condition in this study and in previous studies by our group, ${ }^{2}$ an association between increased plasma levels of the acute phase protein fibrinogen with reduced lung function and increased risk of COPD has recently been reported. ${ }^{3}$ Yasuda et al also reported enhanced CRP levels in patients with stable COPD ${ }^{4}$ It should be noted from these studies ${ }^{24}$ that only part of the patient population exhibited enhanced acute phase protein levels, as was also the case in our study. This indicates that, although all patients were in a clinically stable condition, subgroups can be discriminated based upon inflammatory characteristics. This could be a factor contributing to the discrepancy between the studies by Gompertz et $a l^{5}$ and ours. No relationship was observed between CRP level and severity of disease, ${ }^{4}$ whereas separation of patients into normometabolic and hypermetabolic subgroups revealed enhanced levels of CRP in the latter group. ${ }^{2}$ Further research is needed to elucidate the cause for the production of these acute phase proteins in subgroups of clinically stable COPD patients and its involvement in the pathogenesis of the disease. It is of interest to note that, although only some of the clincally stable patients had enhanced CRP levels, almost all patients who had an exacerbation of disease had increased CRP levels on day 1 of the exacerbation which declined during treatment.

We agree with Dr Kelly that treatment with corticosteroids could affect the leucocyte count in patients with clinically stable COPD. As reported in our paper, increased circulating levels of leucocytes were observed in the subgroup of clinically stable COPD patients treated with oral corticosteroids compared with those who did not receive oral corticosteroids. However, comparison of subgroups of patients without corticosteroid treatment (oral or inhaled or both) with control subjects still revealed significantly increased leucocyte counts (data not shown). This indicates that the enhanced levels of circulating leucocytes are not solely due to corticosteroid use, and could be a marker of the systemic inflammatory process in COPD. In line with this hypothesis, Noguera et al reported enhanced circulating levels of polymorphonuclear cells in patients with stable COPD, none of whom had received steroids before the start of the study (oral or inhaled). ${ }^{6}$

As discussed in our paper, administration of prednisolone during treatment of an exacerbation is most probably the cause for the observed rise in leucocyte counts. In order to determine the effect an of exacerbation on leucocyte counts, studies are currently being performed in our hospital in which blood from patients with an exacerbation is collected before the start of treatment.

COPD comprises a heterogeneous group of conditions characterised by chronic airflow limitation and destruction of lung parenchyma with clinical manifestations of dyspnoea, cough, sputum production, and impaired exercise tolerance. The definition of an acute exacerbation of COPD is still imprecise, and is generally based on varying combinations of symptoms. Rodriguez-Roisin et a suggested staging COPD exacerbations based on use of health care. ${ }^{7}$ They defined three levels of severity: mild, moderate and severe. During a mild exacerbation the patient has an increased need for medication which he/she can manage in their own environment; patients with a moderate exacerbation have an increased need for medication and need to seek additional medical assistance; the patient with a severe exacerbation recognises obvious and/or rapid deterioration in his/her condition requiring admission to hospital. Based on this definition, the patients included in our study were suffering from severe exacerbations of disease. Only limited information is so far available concerning (changes of) inflammatory markers during exacerbations.

In our study the kinetics of pro- and anti-inflammatory markers have been analysed in patients with COPD during the first 7 days in hospital for an exacerbation of the disease. The results showed a significant decline in systemic levels of both CRP (at day 3) and LBP (at day 7) compared with day 1, whereas levels of the anti-inflammatory mediator soluble IL-1 receptor II dramatically increased (until day 5). This change in levels of inflammatory mediators may contribute to the clinical improvement of the patients. Additional studies are required to obtain more insight into the role of the inflammatory processes in the pathogenesis of exacerbations which could contribute to measurable parameters, in order to define the severity or outcome of disease more accurately.

M A Dentener, E C Creutzberg, E F M Wouters

Department of Pulmonology, Maastricht University, Nutrition and Toxicology Research Institute Maastricht (Nutrim), Maastricht, The Netherlands; Mieke.Dentener@pul.unimaas.nl

\section{References}

1 Barnes PJ. Medical progress: chronic obstructive pulmonary disease. N Engl J Med 2000;343:269-80.

2 Schols AM, Buurman WA, Staal van den Brekel AV, et al. Evidence for a relation between metabolic derangements and increased levels of inflammatory mediators in a subgroup of patients with chronic obstructive pulmonary disease. Thorax 1996;51:819-24

3 Dahl M, Tybjærg-hansen A, Vesto J, et al. Elevated plasma fibrinogen associated with reduced pulmonary function and increased risk of chronic obstructive pulmonary disease. Am J Respir Crit Care Med 2001;164:1008-11.

4 Yasuda N, Gotoh K, Minatoguchi S, et al. An increase of soluble Fas, an inhibitor of apoptosis, associated with progression of COPD. Respir Med 1998;92:993-9.

5 Gompertz S, Bayley DL, Hill SL, et al. Relationship between airway inflammation and the frequency of exacerbations in patients with smoking related COPD. Thorax $2001 ; 56: 36-41$

6 Noguera A, Busquets X, Sauleda J, et al Expression of adhesion molecules and $G$ proteins in circulating neutrophils in chronic obstructive pulmonary disease. Am J Respir Crit Care Med 1998;158:1664-8.

7 Rodriguez Roisin R. Toward a consensus definition for COPD exacerbations. Chest 2000;117(5 suppl 2):398-410s. 